\title{
Summary of Dialogues at IPS
}

\author{
Pakistan and Climate Change: Challenge and Response
}

\author{
Activity: \\ Collaboration: \\ Speaker:
}

Chair:

\author{
Roundtable \\ Riphah Institute of Public Policy \\ Dr. Qamar uz Zaman, Advisor, Climate Change, \\ Government of Pakistan \\ Mirza Hamid Hassan, Former Secretary Water \& \\ Power
}

National security has three important dimensions: water security, food security and energy security. The impact of climate change on all these areas is alarming. Pakistan is one of the most vulnerable countries in the world when it comes to the impacts of climate change. The harmful impacts of climate change have led to extreme weather e.g. storms, tornadoes, floods and droughts. There is also evidence of accelerating recession of most glaciers on earth, rainfall variability and changes in marine ecosystems. Infrastructure such as communications and road networks are hit hardest whenever Pakistan experiences floods during the Monsoon season.

Pakistan is suffering severely from climate change being one of the eight top most affected nations despite the country contributes only 0.08 per cent of carbon emissions in the world. The studies done by Global Change Impact Studies Centre (GCISC) have shown that Pakistan is witnessing twice the average global warming elsewhere. The frequency of extreme weather incidents has increased since 1991.

Climate change had also become a victim of geopolitics. The countries with the most greenhouse gas emissions are not willing to take responsibility for the impact of these emissions. America is an example: it contributes around 30 per cent of all emissions but has not signed the Kyoto Protocol. The Kyoto Protocol is an international treaty, ratified by some 191 countries, which binds industrialized countries to reduce their emissions of greenhouse gases.

Government of Pakistan has launched National Climate Change Policy (NCCP). The policy addresses steps Pakistan can take in terms of both adaptation to and mitigation from climate change effects. The policy focuses on issues like water resources, agriculture and disaster preparedness. In water sector, activities like local rainwater harvesting, storage and recycling of waste water are proposed while in the sector of agriculture and livestock, more energy efficient farm mechanization and introduction of climate resistant crops and better breeds of livestock are advocated. In the area of forestry and biodiversity, better research and area specific adaptive plans are called for. For disaster preparedness, a strategic flood forecasting and early warning systems are advocated. In

This segment contains, in a summarized form, the deliberations of some of the seminars, roundtables and discussions at/by IPS during the first half of 2014 . 
health sector, educating and training health personnel about the outbreak of new diseases caused by climate change (e.g. dengue), has been. The measures to be taken for energy efficiency and conservation are highlighted along with mass transit systems in all the big cities and fuel efficient standards for cars. Carbon sequestration in forests is also stressed upon. Finally, the need for capacity building, awareness raising and international cooperation (especially for technology transfer and climate finance) is underlined. The involvement of local communities in the conservation and sustainable use of biodiversity is also emphasized.

Environmental issues are among the most pressing challenges faced by Pakistan which has wide impact on socio economical fabric of society due to severe environmental degradation due to climate change. The risks include: rise in sea level, glacial retreats, floods, higher average temperature and higher frequency of droughts. This is very much pertinent to the agrarian society of Pakistan which is already facing serious challenges in water and agriculture sector. A comprehensive action plan along-with the institutional mechanism to coordinate climate change efforts in three key sectors: water, food/agriculture and energy needs to be developed.

\section{The following recommendations can be forwarded in this context:}

- Climate change is a cross-sectoral issue; the responsibility to face its challenges cannot be handled by a single ministry of climate change at the federal or provincial level. Instead, every ministry, department and agency should develop an environmental or climate change policy of its own keeping in view their respective scopes.

- There are international financing facilities available to help developing countries fund adaptation and mitigation projects, but the capacity to apply for those funds needs to be developed.

- The availability of authenticated, reliable and comparable data testifying the climate change phenomenon is pre-requisite. That data may be housed in some data warehouse/data bank after coordination with number of agencies directly or indirectly involved in climate change process. The scientific analysis of this data is critical.

- Technical training of the human capital is pre-requisite to deal with the issue.

- People should also play their part in protecting the environment and reducing the carbon footprint. Recycling, planting trees and using public transport are some ways people can help. Conservation of energy by switching off extra lights can also bring down greenhouse emissions.

[J anuary 19 - Coordinated by Ms. Waqar-un-Nisa] 


\title{
Pak-US Relations: Status and the Road Ahead
}

\author{
Activity: Seminar \\ Speaker: Dr. Tahir Amin, Director, National Institute of Pakistan \\ Studies, QAU \\ Chair: $\quad$ M. Akram Zaki, Former Secretary General, Ministry of \\ Foreign Affairs Pakistan
}

Ties between Pakistan and the US have an obvious history of fluctuations: with periods of convergences and divergences making the relationship good to bad and even worse over the decades. Currently, the US-Pakistan relations have been on the low end. Being the partners in the War on Terror (WoT), both the US and Pakistan cannot afford complex relations between them. Now, as the US has announced its drawdown of forces from Afghanistan by December 2014, the role and implications for Pakistan become even more significant, in this emerging situation.

Pakistan should tackle this emerging situation by using highly skilful diplomacy; to deal with the US, while diversifying its foreign policy to protect its interests. The stress was laid upon mainly two options for Pakistan in the current situation: to make positive changes in its foreign policy, which will focus not only on the US but on other major powers equally; second, to practice highly skilful diplomacy to come out of the present fix in which it is not being allowed by the US to take decisions in its own national interest vis-à-vis issues like dialogues with Taliban and Pak-Iran gas pipeline project etc.

Ironically, the Pak-US relations are termed as 'Catholic Marriage' on rocks', that it is difficult to maintain stable relationship. The US considered Pakistan as a 'frienmy' and apparently its only interests left with us were in counter terrorism and nuclear nonproliferation. In this situation Pakistan should also evaluate the cost and benefits of its involvement in the war against terrorism and determine the course of future as per its national interest. In order to deal with that situation, Pakistan should diversify its foreign policy and try broadening and strengthening its relations with other major powers such as Russia and China.

It is common knowledge that the age of having friends and enemies between states is over and now all countries look for their national interests by identifying the areas of common and contradictory concerns. It has been stressed that Pakistan's relationship with the US is vital and multifaceted. However, there is still hope that despite having unstable relations, the two countries will have a future of long term cooperation. [January 9 - Coordinated by Ms. Fehmeedah Khalid] 


\section{Development I nitiatives in FATA: I nfrastructure and Beyond}

Activity: Speaker:

Moderator:
Seminar

Brig. Shahid Hasan Ali, Commander.FWO Engineers Group, Dera Ismail Khan; Brig. (r) Said Nazir, Senior Associate, IPS; Mir. Zohair Mahmood, Lead Consultant, Kapabilities; Dr.Fakhr-ul-Islam, Director Pakistan Study Centre, University of Peshawar; Dr. Fazle Rabbi Assistant Professor Department of Economics University of Malakand

Air Cdre. ( $r$ ) Khalid Iqbal Consultant Policy \& Strategic Response, IPRI Member of National Academic Council, IPS

FATA has gained additional significance particularly after $9 / 11$ - be it politics, economy or social dimensions. Discourse on FATA, however, revolves around militancy, insurgency and the counteractions taken by the state. Development, as a whole, finds little mention.

While development itself a comprehensive concept, a number of infrastructure related projects have been initiated. One public-sector infrastructure building organization (Frontier Works Organization FWO] has worked on quite a few of them such as more than 550 kilometers of road has been constructed in FATA, which is more than the length of Lahore-Islamabad Motorway. Even promising was the construction of central trade corridor, which starts from Dera Ismail Khan, passes through the heart of FATA, and connects to Afghanistan through Wana. Furthermore, while indicating the significance of other projects in the area, like the completion of Gomal Zam Dam, has benefitted the agriculture sector in the districts of Tank and Dera Ismail Khan, the electricity generated from the dam will also be provided exclusively to the households of South Waziristan.

FATA is no more a local affair because of the decade long war in its neighborhood it comes into the sharp focus of the world. The area is poorest of the poor, with least education and health facilities. Agriculture is primitive and industry is primarily rested into mini marble factories. So the focus should be on the maintenance and up keeping of the projects with the participation of local population. Emphasis was given to develop a master plan for the reconstruction of hospitals, schools, universities, economic activities, the generation of more employment opportunities because a country's infrastructure is the backbone of economy and serves as a bridge for development and progress.

It was also emphasized that long-term peace can be achieved in FATA through bringing people of FATA into the mainstream, getting sustainable development, enhancing capacity building, reforming education sector and making collective efforts that incorporate people of FATA. While the discussion, the focus was on more engagement, 
involvement and participation of FATA citizens in the regional development initiatives and also advised to carry out the social audit as well as the EIA (Economic Impact Assessment) for these projects. While viewing the development of Fata, it is impossible to overlook the oil and gas potential in Fata that is a significant factor of the development of an area.

For the mainstreaming of FATA, it is necessary to make the inhabitants of the region stakeholders in the process of the infrastructure development initiatives as part of the post-insurgency rehabilitation efforts. To understand FATA and its problems is a huge task, but one thing is clear that whatever system will be introduced in FATA it should be based on people's participation, either it should be Jirga System, Malik's system or Political Agent system, it cannot be successful without people's participation. Empowering the common man, in order to solve the problems of the area is the only key. [May 20 - Coordinated by Ms. Fehmeedah Khalid]

\section{Rising Electricity Tariffs - from NEPRA's Determination to Consumers' Electricity Bill}

Activity:

Speakers:

Chair:
Seminar

Salahuddin Rifai, Former GM, NTDC; Syed Salman Rehman, Asst. Director NEPRA; Syed Riaz Qadeer Bukhari, DG, Customer Service, IESCO, Ameena Sohail, IPS Associate

Mirza Hamid Hassan, Former Secretary Water \& Power

NEPRA determines tariffs for the three sectors namely generation, transmission and distribution. Tariff for Generation Companies are determined on rate of return (cost plus basis) in most cases, under long term (25-30 years) PPAs for Greenfield generation projects. Tariff of Transmission Company is determined on annual cost plus basis (where, in addition to the costs, certain return on equity or assets is allowed). Distribution Companies are mostly given tariffs on cost plus basis, whereas multiyear tariffs have also been determined by NEPRA for KESC.

The Company/ Licensee files a petition for determination of its tariff according to NEPRA Tariff Standard Procedure Rules -1998:

- The Authority on the basis of information decides whether prima facie case exists for admission of the tariff petition;

- In case Authority admits the petition for consideration it gives notice to all the stakeholders through advertisement in the national newspapers inviting them for intervention to participate in the tariff proceedings through personal participation or through written comments;

- After public hearing, based on the evidence provided by the petitioner and the stakeholders, the Authority after due 
diligence determines the tariff and recommends to the Federal Government for notification in the official gazette;

- Generation and Transmission Tariff are determined on cost plus basis.

Tariffs are determined, modified or revised, inter alia, on the basis of procedures prescribed under Rule 17(3) of the NEPRA Tariff Standards \& Procedure Rules, 1998:

- tariffs should allow licensees the recovery of any and all costs prudently incurred to meet the demonstrated needs of their customers

- tariffs should reflect marginal cost principles to the extent feasible, keeping in view the financial stability of the sector

- the tariff regime should clearly identify inter-class and interregion subsidies

- tariffs should, to the extent feasible, reflect the full cost of service to consumer groups with similar service requirements;

- tariffs should take into account Government subsidies or the need for adjustment to finance rural electrification in accordance with the policies of the Government;

The tariff so determined is forwarded to the Federal Government pursuant to the Section 31(4) of the NEPRA Act for notification in the Official Gazette. Federal Government in pursuant to Section 31(4) of NEPRA Act read with Rule 16(12) of Tariff Rules - 1998 may file reconsideration request with reference to determination / decision of the Authority. The Authority within 15 days shall decide upon the matter and intimated to the Federal Government for Notification in the official gazette.

The existing power tariff in the country is Rs14 and with the addition of 17 per cent GST and 3.5 per cent excise duty it becomes Rs16.95, which is the highest in the region. The main reasons for the high tariff rates in resource-rich Pakistan were governance related due to the short-sightedness of policy-makers, corruption, mismanagement, and unavailability of the right people at the right places. The overwhelming share of fossil fuel based power generation is the main cause of the exorbitant per KWH tariff in Pakistan. In India and Bangladesh, the tariff for the same unit is Rs7.36 and Rs5.47 respectively. Even in the US it is equal to Rs8.59.

WAPDA started at 118 MW installed capacity, 700 GWH generation, PKR70 million revenue and 270,000 consumers. The power sector of the country was self-financed at the beginning. Till mid-1980s the power generation of WAPDA increased to about 5700MW through projects build out of its own profits and government loans on 17-18 per cent compound interest. The government stopped providing loans to WAPDA in 1985. 
The load growth during 1960 to 1985 was tremendous: up to 18 per cent annually. The World Bank undertook to finance 60 per cent of development on condition of 40 per cent self-financing by WAPDA out of its own profits. In 1985, the concept of private power generation was introduced and the federal government floated the first tender. In 1988 the first MOU was signed for the furnace-oil based 1292MW Hubco plant out of tens of offers and Pakistan became the first country in the Third World to have private power generation, that too on furnace oil and exorbitant costs.

The analysis of the achievements against planned targets in installed capacity of power generation from 1955 to 2010 shows that the progress from the first five-year plan (1955-60) to the eighth fiveyear plan (1993-98) is quite satisfactory. However, no addition was planned in the ninth five-year plan (1998-2003) and only a deplorable six per cent target was achieved against the planned $7880 \mathrm{MW}$ in the Medium Term Development Framework (2005-2010). Due to this failure, today, the electricity shortfall has reached 3916MW.

The pro-furnace oil government policies for power generation have led to the current energy crisis. The fuel cost in 1994 policy was Rs0.60/KWH, which increased to Rs15 in 2013 and might reach Rs100 in 2025 if the international oil prices continued to increase with the same pace.

There is very high and unaffordable tariff for Pakistanis. There is huge Demand-Supply Gap of 3000-6000 MW .industries without power and development of Industries is coming to a standstill. There are Huge Job losses and unemployment and underemployment both are increasing. Gross Domestic Product is not growing; according to a latest study by Dr. Hafeeez Pasha, one KWH not supplied to the industry causes a loss of Rs. 53/unit. As a result there are unrest, demonstrations, and power riots.

There is need to set the things right. There is a lesson to learn from our faults. It should be analyzed that why the cost is becoming higher? In Pakistan, the labor cost is cheap, the construction of basic material is cheap than that of U.K, U.S and India. But electricity in Pakistan is expensive because of wrong choices, wrong actions, wrong people and wrong decisions. [J anuary 29 - Coordinated by Ms. Waqarun-Nisa] 


\title{
Conference on Disarmament and Pakistan
}

\author{
Activity: \\ Roundtable \\ Speakers: \\ Mr. Khalid Banuri, Strategic Plans Division (SDP), \\ Amb. Sarwar Naqvi, former Pakistani envoy and \\ Ms. Haleema Sadia, SPD) \\ Chairperson: $\quad$ Tariq Osman Hyder, former senior diplomat
}

One of the major tasks of the $C D$ is to negotiate nuclear disarmament. Yet, after the lapse of more than three decades, the goal of negotiating and concluding a Convention on nuclear disarmament is as elusive as ever. In the past four years some states have taken upon themselves to shift the goal-post in terms of priorities on the international security agenda. Their efforts to project the FMCT as the "new" priority and the only "ripe" issue betray facts on the ground. However, in recent years, there is an increasing realization in delegates of different countries that $\mathrm{CD}$ is not synonymous to FMCT. It is noticeable change.

On the issue of FMCT, still there are few countries which are in view that Pakistan is responsible for the stalemate in $C D$. On the other hand, Pakistan considers that FMCT is a Pakistan-specific treaty. Pakistan has concerns on the large stockpiles of plutonium in India, that's why it is demanding to include existing stockpiles in any such treaty. Pakistan also feels that its security environment provide its neighbors with advantage in term of existing nuclear weapons and fissile material stock. Like every state Pakistan's position on FMCT is shaped by its security imperative. There are many compulsions but four of them are very important 1 ) Indo-US nuclear deal 2) issue of aggressive doctrines by India 3) Indian interest in Ballistic Missile Defense 4) bringing India into the fold of Nuclear and other export control cartels, and in this regard NSG is the major area. Pakistan considers that if India enters into NSG, it will not be suitable for Pakistan. NSG works with consensus and deals with high technology; if India will be part of such consensus, India will impede the access to high technology for perfectly legitimate civilian uses for Pakistan.

Pakistan's principle stance on the treaty is that it is ready to enter into the negotiations on a FMCT if the treaty addresses: the asymmetry in stockpiles; reduces the existing stockpiles of nuclear materials by each party as a disarmament measure; and addresses Pakistan's security concerns emanating from India's growing nuclear and conventional capabilities. Numbers of supporters on Pakistan's principle stance on FMCT are increasing. Perhaps it was lack of support that FMCT resolution was not even tabled for adoption in the UNGA during the current years.

Pakistan also considered that within FMCT there are problems like broader framework i.e. the question of stockpile and verification. Pakistan wanted to broaden the scope of FMCT by adding the agenda of disarmament and the elimination of existing stock of fissile material 
including enriched uranium and plutonium. Pakistan's position is very clear: Pakistan wants non-discriminatory, multilateral and international effectively verifiable treaty banning the production of fissile material for nuclear weapons or other nuclear explosive devices. But some influential entities/ major powers do not allow any progress on this agenda items in CD.

A change was observed for the first time in six years when UN Secretary General's statement did not even mention FMCT during his address to CD. This could be considered as a sign of recognition of realities. On other hand, the US acting sectary of Arms Control and International Security Rose Goettemoller's statement of $4^{\text {th }}$ Feb reiterated the FMCT mantra and rhetoric. She stated that US is very particular about this issue of FMCT in $C D$ and will be moving force behind to make this issue viable in CD. She also restated US position in the context by asserting that "For US FMCT is an essential pre-requisite for eventual nuclear disarmament". Pakistan disagrees with the US at this point. But the significance is lessened in view of emerging and shifting focus on disarmament, although the ground realties may limit the impact.

Undue urgency is indicated in its efforts for fast tracking negotiations on fissile material while showing little or no interest to proceed on remaining points on its agenda. Pakistan has always advocated universal nuclear disarmament and also supports to begin the talks co-concurrently on all agenda items of CD. In Pakistan's view disarmament is an important issue even more than FMCT. Now there is also trepidation that because of FMCT, other issues like general complete disarmament have affected. Pakistan's stance is that unless a treaty unambiguously covers the questions of reducing existing stockpiles of fissile material, it would contribute to nuclear disarmament. $C D$ is trying to move forward on its agenda points. However, its approach is lopsided. Pakistan has reiterated again and again to 120 members of NAM to convene the $4^{\text {th }}$ Special Session of the General Assembly on Disarmament, to revive a global consensus to ensure elimination of nuclear weapons while meeting the security concerns of all states. [February 6 - Coordinated by Ms. Fatima Habib] 